\title{
Quantitative analysis of time-resolved infrared stimulated luminescence in feldspars
}

Pagonis, Vasilis; Ankjærgaard, Christina; Jain, Mayank; Chithambo, Makaiko L.

Published in:

Physica B: Condensed Matter

Link to article, DOI:

10.1016/j.physb.2016.06.013

Publication date:

2016

Document Version

Peer reviewed version

Link back to DTU Orbit

Citation (APA):

Pagonis, V., Ankjærgaard, C., Jain, M., \& Chithambo, M. L. (2016). Quantitative analysis of time-resolved infrared stimulated luminescence in feldspars. Physica B: Condensed Matter, 497, 78-85.

https://doi.org/10.1016/j.physb.2016.06.013

\section{General rights}

Copyright and moral rights for the publications made accessible in the public portal are retained by the authors and/or other copyright owners and it is a condition of accessing publications that users recognise and abide by the legal requirements associated with these rights.

- Users may download and print one copy of any publication from the public portal for the purpose of private study or research.

- You may not further distribute the material or use it for any profit-making activity or commercial gain

- You may freely distribute the URL identifying the publication in the public portal

If you believe that this document breaches copyright please contact us providing details, and we will remove access to the work immediately and investigate your claim. 


\section{TITLE PAGE}

TITLE:

QUANTITATIVE ANALYSIS OF TIME-RESOLVED INFRARED STIMULATED LUMINESCENCE IN FELDSPARS

\section{Author names and affiliations}

Vasilis Pagonis ${ }^{1, *}$ Christina Ankjærgaard ${ }^{2}$, Mayank Jain ${ }^{3}$, Makaiko L. Chithambo ${ }^{4}$

${ }^{1}$ McDaniel College, Physics Department, Westminster, MD 21157, USA

2 Soil Geography and Landscape group \& Netherlands Centre for Luminescence dating, Wageningen University, PO Box 47, 6700 AA Wageningen, The Netherlands

${ }^{3}$ Center for Nuclear Technologies, Technical University of Denmark, DTU Risø Campus, Roskilde, Denmark

${ }^{4}$ Department of Physics and Electronics, Rhodes University, PO BOX 94, Grahamstown 6140, South Africa

\section{* Corresponding author}

Vasilis Pagonis

Email: vpagonis@mcdaniel.edu

Phone: (410)-857-2481 Fax: (410)-386-4624 


\title{
QUANTITATIVE ANALYSIS OF TIME-RESOLVED INFRARED STIMULATED LUMINESCENCE IN FELDSPARS
}

Vasilis Pagonis $^{1, *}$ Christina Ankjærgaard ${ }^{2}$, Mayank Jain ${ }^{3}$, Makaiko L. Chithambo ${ }^{4}$

${ }^{1}$ McDaniel College, Physics Department, Westminster, MD 21157, USA

2 Soil Geography and Landscape group \& Netherlands Centre for Luminescence dating, Wageningen University, PO Box 47, 6700 AA Wageningen, The Netherlands

${ }^{3}$ Center for Nuclear Technologies, Technical University of Denmark, DTU Risø Campus, Roskilde, Denmark

${ }^{4}$ Department of Physics and Electronics, Rhodes University, PO BOX 94, Grahamstown 6140, South Africa

\begin{abstract}
Time-resolved infrared-stimulated luminescence (TR-IRSL) from feldspar samples is of importance in the field of luminescence dating, since it provides information on the luminescence mechanism in these materials. In this paper we present new analytical equations which can be used to analyze TR-IRSL signals, both during and after short infrared stimulation pulses. The equations are developed using a recently proposed kinetic model, which describes localized electronic recombination via tunneling between trapped electrons and recombination centers in luminescent materials. Recombination is assumed to take place from the excited state of the trapped electron to the nearest-neighbor center within a random distribution of luminescence recombination centers. Different possibilities are examined within the model, depending on the relative importance of electron de-excitation and recombination. The equations are applied to experimental TR-IRSL data of natural feldspars, and good agreement is found between experimental and modeling results.
\end{abstract}

Key Words: stimulated luminescence emission, feldspars, tunneling, time-resolved experiments Corresponding author. Email: vpagonis@mcdaniel.edu 


\section{INTRODUCTION}

When an insulating material is exposed to ionizing radiation, some of the free electrons resulting from the interaction will end up being trapped at defects in the crystal. The concentration of such trapped charges is a function of the radiation dose, and this relationship form the basis of trapped-charge dating methods. When the crystal is subsequently exposed to optical excitation, some of the trapped electrons can be released from the traps and recombine, radiatively, with holes trapped at appropriate centers to produce optically stimulated luminescence, which is widely used in sediment dating. In this paper we are concerned with feldspars, for which the excitation spectra of the optically stimulated luminescence have a prominent peak at $\sim 1.44 \mathrm{eV}$. The defects related to this resonance also exhibit tunneling effects associated with a variable tunneling distance. For a summary of previous work on feldspars the reader is referred to the books by Chen and Pagonis (2011) and Bøtter-Jensen et al. (2003).

During the past decade numerous experimental and modeling studies have established that quantum mechanical tunneling is the dominant mechanism for production of luminescence signals in feldspars (Wintle, 1973; Visocekas, 1985; Bailiff and Poolton, 1991; Duller et al., 1993; Visocekas et al., 1994; Duller, 1997; Huntley and Lamothe, 2001; Poolton et al, 2002a, 2002b; Bøtter-Jensen et al., 2003; Li and Li 2008, 2010; Kars et al. 2008; Larsen et al., 2009; Huntley, 2006). While many of these studies are concerned with tunneling taking place from the ground state of the trap, research has also supported the existence of tunneling processes taking

place from the excited state of the trap, as well as in combination with charge migration through the conduction band-tail states (Jain and Ankjærgaard, 2011; Ankjærgaard et al., 2009; Thomsen et al., 2008; 2011; Andersen et al., 2012; Pagonis et al., 2012a; Kars et al., 2013).

Jain et al. (2012) developed a model in which localized electronic recombination of pairs of trapped electrons and recombination centers takes place via the excited state of the trapped electron, to the nearest center within a random distribution of them. They successfully simulated both thermally stimulated luminescence (TL) and optically stimulated luminescence (OSL), and found that a power law behavior can occur for OSL. This model was examined by Kitis and Pagonis (2013), to obtain analytical solutions for four different experimental modes of stimulation: TL, OSL, linearly modulated OSL (LM-OSL) and isothermal TL. These analytical solutions have been used in several recent experimental studies to fit luminescence from a 
variety of feldspars and apatites (Polymeris et al., 2014; Sfampa et al., 2014; Pagonis et al., 2013; Pagonis et al., 2014a; Pagonis et al., 2014b; Sfampa et al., 2015).

Time-resolved luminescence data provide a method of distinguishing between the different recombination routes in a variety of materials. Time-resolved optically stimulated and infrared stimulated luminescence (TR-OSL and TR-IRSL) from feldspars have been the subject of several recent experimental studies. Jain and Ankjærgaard (2011) compared time resolved luminescence from feldspars using mainly IR, green and blue stimulations and examined the changes occurring as a function of photon energy, storage time after irradiation, and thermal or optical pre-treatments of the samples. These experimental results were interpreted within the framework of a model containing several possible pathways for charge movement, namely from the dosimetric trap via the ground and excited states of the trap, via the band tail states and through the conduction band.

Several experimental studies have identified five ranges of lifetimes in TR-IRSL signals, namely 30-50 ns, 300-500 ns, 1-2 $\mu \mathrm{s}, ~ 5 \mu \mathrm{s}$, and > $10 \mu \mathrm{s}$ (Sanderson and Clark, 1994; Clark et al., 1997; Clark and Bailiff, 1998; Chithambo and Galloway, 2000; Denby et al., 2006; Tsukamoto et al., 2006). Some of these lifetimes were interpreted as due to internal transitions within the recombination centers (Clark and Bailiff, 1998). Morthekai et al. (2012) studied TRIRSL from four feldspar mineral specimens, by assuming that de-trapped electrons undergo random walk in the band-tail states before recombining by tunneling. The hopping time for the random walk was derived from the OFF-time data of TR-IRSL experiments, and the extracted parameters were shown to be consistent with the variable range hopping mechanism of the Mott kind. Pagonis et al. (2012b) also analyzed TR-IRSL data from the same four natural feldspars samples, in terms of the sum of an exponential and a stretched exponential function.

The technology of measuring such time-resolved signals has been greatly improved during the past 10 years, and modeling advancements have contributed to a better understanding of the luminescence process. These recent developments in both experiments and models prompted us to re-examine the topic of the shape and mathematical characterization of such signals.

In this paper we use the model of Jain et al. (2012) to describe the shape of TR-IRSL signals during and following short infrared pulses.

The goals of the present paper are: 
(a) To investigate whether the model of Jain et al. (2012) can be used to describe experimental TR-IRSL data from feldspars, in the microsecond time scale.

(b) To fit experimental TR-IRSL data from feldspars, both during and after short excitation pulses.

(c) To examine different outcomes from the model, depending on the values of the various kinetic papers.

\section{SAMPLES AND EXPERIMENTAL SETUP}

The TR-IRSL signals from two feldspar samples are analyzed in this paper. The first set of TR-IRSL data was previously published by Morthekai et al. (2012) on sample FL1, a museum specimen of feldspar. X-ray diffraction analysis indicated that FL1 is a microcline also containing diopside and albite. Assuming that feldspars contain only $\mathrm{K}, \mathrm{Na}$ and $\mathrm{Ca}$, the ratio of $\mathrm{K}: \mathrm{Na}$ :Ca was calculated and these values place FL1 in the alkali feldspar series. The samples were crushed gently using an agate mortar and sieved to obtain the $90-150 \mathrm{~mm}$ size fraction, which was used without any further chemical treatment. The second sample is the potassium rich feldspar fraction ( $\left.\mathrm{K}-\mathrm{AlSi}_{3} \mathrm{O}_{8}\right)$ of a glacio-fluvial sediment from Jameson land, East Greenland with a grain size 106-180 $\mu \mathrm{m}$ (lab. code 951002FK). A few milligrams of the samples were mounted on stainless steel disks using Silkospray silicone oil.

Measurements were carried out on a Risø TL/OSL-20 reader equipped with an integrated pulsing option to control the IR LEDs, and a Photon Timer attachment to record the TR-IRSL. The IR stimulation was performed with an $870 \mathrm{~nm}$ (FWHM $40 \mathrm{~nm}$ ) LED array delivering 100 $\mathrm{mW} / \mathrm{cm}^{2}$. The stimulated luminescence emission was detected using a photomultiplier tube (EMI 9235QB; 30\% QE at $395 \mathrm{~nm}$ ), and the time-resolved signals for sample FL1 were detected using a combination of BG-39 (2 mm) and Corning 7-59 (4 mm) filters (transmitting photons at $395 \pm 50 \mathrm{~nm}$ ). The TR-IRSL signals for the potassium rich feldspar fraction were detected in the UV emission (U340 filter, $7.5 \mathrm{~mm}$ ).

For sample FL1 the TR-IRSL signals were measured for a stimulation temperature of 50 ${ }^{\circ} \mathrm{C}$, after the sample was given a dose of $61.8 \mathrm{~Gy}$, and preheated to $280^{\circ} \mathrm{C}$ for $60 \mathrm{~s}$, using an $\mathrm{ON}-$ time of $50 \mu \mathrm{s}$ and an OFF-time $100 \mu \mathrm{s}$. For sample 951002FK the TR-IRSL curves were measured at a stimulation temperature of $50^{\circ} \mathrm{C}$, after the sample was given a dose of $70 \mathrm{~Gy}$, and then preheated to $250^{\circ} \mathrm{C}$ for $60 \mathrm{~s}$, using an ON-time of $500 \mu \mathrm{s}$, and an OFF-time of $300 \mu \mathrm{s}$. 
An important experimental consideration when fitting the TR-IRSL data is the switchingoff speed (or the fall-time) of the LEDs. The diode intensity after the end of the excitation period reduces very quickly to $\sim 5 \%$ of the initial intensity, but it takes an additional $\sim 3 \mu$ for the IR diodes to reach a light level of less than $1 \%$ of the stimulation light level during the pulse. Therefore, for the analysis of the experimental data in this paper, all data points for $t<3 \mu$ s are not used in the fitting process, since they may represent a mixture of the luminescence signal from the sample and the signal during the LED switching-off.

\section{ANALYSIS OF TIME-RESOLVED EXPERIMENTS USING THE MODEL BY JAIN ET AL. (2012)}

In this section we use the model and notation of Jain et al. (2012, 2015). The model assumes a random distribution of trapped electrons and a random distribution of nearest-neighbor recombination centers, and that emission of luminescence is a result of tunneling recombination of a trapped electron from the excited state of the trap, excited by optical stimulation. Figure 1 illustrates the different transitions considered within this model: Optical excitation of electrons from the ground state into the excited state of the trap during IR stimulation (transition i). From the excited state, the electrons can either de-excite back into the ground state (transition ii) or tunnel from the excited state to the recombination center (transition iii). The physical assumptions in the model of Jain et al. (2012) are summarized in Table 1 of their paper, and includes that the concentration of centers is assumed to be much larger than the concentration of trapped electrons, and that an electron tunnels only to its nearest center. In the exact form of the model presented by Jain et al. (2015), the differential equations are:

$$
\begin{aligned}
& \frac{\partial n_{g}\left(r^{\prime}, t\right)}{\partial t}=-A n_{g}\left(r^{\prime}, t\right)+B n_{e}\left(r^{\prime}, t\right) \\
& \frac{\partial n_{e}\left(r^{\prime}, t\right)}{\partial t}=A n_{g}\left(r^{\prime}, t\right)-B n_{e}\left(r^{\prime}, t\right)-\frac{n_{e}\left(r^{\prime}, t\right)}{\tau\left(r^{\prime}\right)} \\
& L(t) \propto \int_{0}^{\infty} \frac{n_{e}\left(r^{\prime}, t\right)}{\tau\left(r^{\prime}\right)} d r^{\prime} \\
& \tau=b^{-1} \exp \left(\frac{r^{\prime}}{\left(\rho^{\prime}\right)^{1 / 3}}\right)
\end{aligned}
$$


The parameters and symbols used in the model are as follows. As discussed in Jain et al. (2012), it is advantageous from a mathematic appoint of view to transform the absolute distance $r$ between the trapped electron and recombination center into a dimensionless distance parameter which is defined by $r^{\prime}=(4 \pi \rho / 3)^{1 / 3} r$, where $\rho$ represents the actual number density of centers in the material; with such a transformation the nearest neighbor distribution becomes independent of the true number density of the centers. Similarly one introduces the dimensionless number density of recombination centers parameter by $\rho^{\prime}=(4 \pi \rho / 3) \alpha^{-3}$, where $\alpha$ is the potential barrier penetration constant (Huntley, 2006). By introducing these dimensionless parameters, one can describe the nearest neighbor distribution in the material in a manner that does not depend on the actual number density $\rho$ of centers.

$n_{g}\left(r^{\prime}, t\right)$ and $n_{e}\left(r^{\prime}, t\right)$ are the instantaneous concentrations of electrons in the ground state and in the excited state correspondingly. These concentrations are functions of time $t$ and of $r^{\prime}$. A is the excitation rate from the ground to the excited state (Transition i, Fig. 1) given by $A=\sigma(E) I$. Here $E$ is the optical stimulation photon energy, $\sigma(E)$ is the optical absorption cross-section and $I$ is the photon flux. De-excitation from the excited state back in to the ground state (Transition ii, Fig. 1 ) is governed by the relaxation rate $B$, and $L(t)$ is the instantaneous photon emission rate resulting from tunneling recombination via the excited state (Transition iii, Fig. 1). The attempt-to-tunnel frequency is denoted by $b$ in Jain et al. (2015) and in equation (4) above. In general, there is no physical relationship between the two quantities $B, b$ and these two parameters can have very different numerical values.

\subsection{Solution of the differential equations during a short IR excitation pulse}

During a TR-IRSL experiment we assume that the excitation pulse is sufficiently short, such that only a small number of electrons are raised from the ground state into the excited state of the trap by IR excitation. Thus, during and after a TR-IRSL pulse, the concentration of electrons in the ground state $n_{g}\left(r^{\prime}, t\right)$ does not change significantly and so one can approximate $n_{g}\left(r^{\prime}, t\right)=n_{g}\left(r^{\prime}, 0\right)$ in equation (2), where $n_{g}\left(r^{\prime}, 0\right)$ is the concentration of electrons at the beginning of the TR-IRSL experiment. Equation (2) then yields: 


$$
\frac{\partial n_{e}\left(r^{\prime}, t\right)}{\partial t}=A n_{g}\left(r^{\prime}, 0\right)-n_{e}\left(r^{\prime}, t\right)\left[B+\frac{1}{\tau\left(r^{\prime}\right)}\right]
$$

The solution is:

$$
n_{e}\left(r^{\prime}, t\right)=\frac{A n_{g}\left(r^{\prime}, 0\right)}{B+\frac{1}{\tau\left(r^{\prime}\right)}}\left(1-e^{-\left[B+\frac{1}{\tau\left(r^{\prime}\right)}\right]}\right) \quad \text { for } 0<t<t_{o}, \quad \text { (DURING PULSE) }
$$

where $t_{o}$ represents the stimulation pulse length. Thus for a given distance $r^{\prime}$ the concentration of electrons $n_{e}\left(r^{\prime}, t\right)$ in the excited state will grow during the optical excitation period.

The luminescence intensity $L_{O N}(t)$ during the IR pulse can be found from equations (3) and (6):

$$
L_{O N}(t) \propto \int_{0}^{\infty} \frac{n_{e}\left(r^{\prime}, t\right)}{\tau\left(r^{\prime}\right)} d r^{\prime}=\int_{0}^{\infty} \frac{A n_{g}\left(r^{\prime}, 0\right)}{1+B \tau\left(r^{\prime}\right)}\left(1-e^{-\left[B+\frac{1}{\tau\left(r^{\prime}\right)}\right] t}\right) \quad \text { for } 0<t<t_{o}
$$

For a freshly irradiated sample the initial distribution of electrons $n_{g}\left(r^{\prime}, 0\right)$ at the beginning of the experiment is assumed to be given by the probability distribution function:

$$
n_{g}\left(r^{\prime}, 0\right)=P\left(r^{\prime}\right)=3 n_{0}\left(r^{\prime}\right)^{2} \exp \left[-\left(r^{\prime}\right)^{3}\right]
$$

where $n_{0}$ is the total initial concentration of trapped electrons. Combining equations (7) and (8) we obtain the desired equation for the luminescence intensity during the excitation period of the pulse:

$$
L_{O N}(t)=\int_{0}^{\infty} \frac{3 n_{0} A\left(r^{\prime}\right)^{2} \exp \left[-\left(r^{\prime}\right)^{3}\right]}{1+B \tau\left(r^{\prime}\right)}\left(1-e^{-\left[B+\frac{1}{\tau\left(r^{\prime}\right)}\right]}\right) d r^{\prime} \quad \text { for } 0<t<t_{o} \quad \text { (DURING PULSE) (9) }
$$

One can obtain $L_{O N}(t)$ from this equation for any set of parameters $n_{0}, A, B, b, \rho^{\prime}, t_{o}$ using numerical integration.

The concentration $n_{e}\left(r^{\prime}, t\right)$ is a function of the distance parameter $r^{\prime}$, and of the elapsed excitation time $t$ during the excitation pulse. An example of this function calculated from Equation (6) for the set of parameters $n_{0}=10^{8} \mathrm{~cm}^{-3}, A=10^{3} \mathrm{~s}^{-1}, \mathrm{~s}=10^{8} \mathrm{~s}^{-1}, B=10^{5} \mathrm{~s}^{-1}$, $\rho^{\prime}=0.010$ is shown in Figure 2a. This simulated data shows that as the excitation time $t$ 
increases during the pulse, the distribution $n_{e}\left(r^{\prime}, t\right)$ also increases with the excitation time $t$, and shifts to higher values of the distance $r^{\prime}$. This result makes physical sense, since one would expect that as the excitation time increases, the pairs with shorter distances have recombined, therefore, the distribution shifts to the higher values $r^{\prime}$, and more distant pairs may be accessed by the optical excitation process . It is noted that a somewhat similar change in the shape of the distribution of trapped electron-center distances during natural irradiation of feldspars was found in the detailed modeling and experimental study of anomalous fading by Li and Li (2008).

Figure 2b shows an example of the corresponding $L_{O N}(t)$, calculated by numerical integration of equation (9). The same set of parameters is used as in Figure 2a, for two different values of the charge density $\rho^{\prime}=0.001$ and $\rho^{\prime}=0.010$.

\subsection{Solution of the differential equations after the end of the IR excitation pulse}

The solution to $n_{e}\left(r^{\prime}, t\right)$ after the end of the infrared stimulation, i.e. when the LED is turned OFF, is obtained by setting $A=0$ into Equation (5) :

$\frac{\partial n_{e}\left(r^{\prime}, t\right)}{\partial t}=-n_{e}\left(r^{\prime}, t\right)\left[B+\frac{1}{\tau\left(r^{\prime}\right)}\right]$.

The solution of this equation is a simple decaying exponential of the form:

$n_{e}\left(r^{\prime}, t\right)=n_{e}\left(r^{\prime}, t_{o}\right) e^{-\left[B+\frac{1}{\tau\left(r^{\prime}\right)}\right]\left(t-t_{o}\right)} \quad$ for $t>t_{o} \quad$ (AFTER PULSE)

where $n_{e}\left(r^{\prime}, t_{0}\right)$ represents the concentration $n_{e}\left(r^{\prime}, t\right)$ at the end of the excitation pulse.The value $n_{e}\left(r^{\prime}, t_{0}\right)$ can be obtained easily from equation (6) by setting $t=t_{o}$. The luminescence intensity $L_{\text {OFF }}(t)$ after the end of the IR pulse will be found by combining equations (3) and (11): $L_{\text {OFF }}(t)=\int_{0}^{\infty} \frac{n_{e}\left(r^{\prime}, t_{o}\right) e^{-\left[B+\frac{1}{\tau\left(r^{\prime}\right)}\right]}}{\tau\left(r^{\prime}\right)} d r^{\prime} \quad$ for $t>t_{o}$

(AFTER PULSE).

After the end of the excitation pulse the distribution of electrons $n_{e}\left(r^{\prime}, t\right)$ in the excited state is given by equation (11) and is shown in Fig. 3a for the charge density $\rho^{\prime}=0.010$ and for different times after the stimulating IR light has been turned off. This simulation was carried out using the 
same set of parameters as in Fig. 2. Note that since $t_{o}=25 \mu$ s in Fig. 3, the solid curve in Fig 3a corresponds to the dotted line in Fig. 2a. Figure 3a shows that as the time elapses after the end of the pulse, the number of electrons $n_{e}\left(r^{\prime}, t\right)$ decreases with the elapsed time $t$, and the peak shifts to higher values of the distance $r^{\prime}$ representing more distant - pairs. Figure 3b shows an example of $L_{O F F}(t)$ calculated from Eq. (12) by numerical integration with the same set of parameters as in Fig. 3a. It is seen from Fig. 2b and 3b, that a lower density causes a slower build up and decay of luminescence, respectively.

Figure 4a shows the rise of the IR during the ON-time, and the decay during the OFF-time for a simulation of stimulation pulses with different excitation periods $t_{o}$, using the same model parameters as in Fig. 3. Figure 4b shows the decay after the pulses in Fig. 4a for $t>t_{o}$, normalized to the start of the decay. An important conclusion from Fig. 4b is that the duration of the excitation period clearly affects the rate of decay and the shape of the pulses after the LED has been turned off; this is because of the progressive shift in the peak of the distribution with the duration of the excitation (Figure 2a). This is in contrast to the situation with quartz, where the rate of decay of the pulses is independent of the duration of the excitation period $t_{o}$ (Pagonis et al., 2011).

\subsection{Solution of the differential equations for $B<<1 / \tau$}

In the presence of very weak de-excitation (Transition ii, Fig. 1) from the excited state back into the ground state, $B<<1 / \tau$ (or equivalently $B \tau<<1$ ), one can approximate $B+1 / \tau \square 1 / \tau$ and equations (6) and (11) become respectively:

$$
\begin{aligned}
& n_{e}\left(r^{\prime}, t\right)=A n_{g}\left(r^{\prime}, 0\right) \tau\left(r^{\prime}\right)\left(1-e^{-\frac{t}{\tau\left(r^{\prime}\right)}}\right) \quad \text { for } 0<t<t_{o}, \quad \text { (DURING PULSE) } \\
& n_{e}\left(r^{\prime}, t\right)=n_{e}\left(r^{\prime}, t_{o}\right) e^{-\frac{t}{\tau\left(r^{\prime}\right)}} \quad \text { for } t>t_{o} .
\end{aligned}
$$

The luminescence intensity $L_{O N}(t)$ observed during the IR pulse will be found from equation (9) which for $B \tau<<1$ becomes:

$$
L_{O N}(t)=\int_{0}^{\infty} 3 n_{0} A r^{\prime 2} \exp \left[-\left(r^{\prime}\right)^{3}\right]\left(1-e^{-t / \tau\left(r^{\prime}\right)}\right) d r^{\prime} \quad \text { for } 0<t<t_{o}
$$


By using the normalization property of the probability density function (PDF), $\int_{0}^{\infty} 3\left(r^{\prime}\right)^{2} \exp \left[-\left(r^{\prime}\right)^{3}\right] d r^{\prime}=1$, equation (15) becomes:

$L_{\text {ON }}(t)=n_{0} A\left[1-\int_{0}^{\infty} 3 r^{\prime 2} \exp \left[-\left(r^{\prime}\right)^{3}\right] e^{-\frac{t}{\tau\left(r^{\prime}\right)}} d r^{\prime}\right]$.

The integral appearing in equation (16) has been studied previously extensively (Tachiya and Mozumder, 1974; Huntley, 2006; Jain et al., 2012; Pagonis and Kitis, 2015) and can be approximated by the expression $\exp \left[-\rho^{\prime} \ln (z b t)^{3}\right]$, where $b$ denotes the tunneling frequency, and $z=1.8$ is an empirical correction factor which is introduced in order to describe accurately the result of the numerical integration. With this substitution for the integral, one obtains from equation (16):

$$
L_{\text {ON }}(t)=n_{0} A\left[1-\exp \left[-\rho^{\prime} \ln (z b t)^{3}\right]\right] \quad \text { for } 0<t<t_{o} \quad \text { (DURING PULSE) }
$$

Similarly starting with the approximation $B \tau<<1$ one obtains from Equation (12):

$$
L_{\text {OFF }}(t)=\int_{0}^{\infty} A n_{g}\left(r^{\prime}, 0\right) e^{-t / \tau\left(r^{\prime}\right)} d r^{\prime}-\int_{0}^{\infty} A n_{g}\left(r^{\prime}, 0\right)\left(e^{-\left(t+t_{0}\right) / \tau\left(r^{\prime}\right)}\right) d r^{\prime} .
$$

The integrals in this equation can again be approximated by the expressions $\exp \left[-\rho^{\prime} \ln (z b t)^{3}\right]$ and $\exp \left[-\rho^{\prime} \ln \left[z b\left(t+t_{o}\right)\right]^{3}\right]$ to obtain:

$$
L_{\text {OFF }}(t)=A n_{o}\left\{\exp \left[-\rho^{\prime} \ln (z b t)^{3}\right]-\exp \left[-\rho^{\prime} \ln \left[z b\left(t+t_{o}\right)\right]^{3}\right]\right\} \quad \text { for } t>t_{o} \text { (AFTER PULSE) (19) }
$$

Summarizing, the analytical equations (17) and (19) can be used to fit the luminescence intensity during and after the IR pulse in a TR-IRSL experiment, and they should be applicable under the condition of weak de-excitation, $B<<1 / \tau$. It must be noted that strictly speaking from a mathematical point of view, the inequality $B<<1 / \tau$ may not be satisfied at very small times and very small radii. This will most likely result in the equations in this section being less accurate at small times near the beginning of the TR-IRSL experiments.

\subsection{Solution of the differential equations for $B>>1 / \tau$}

In the presence of strong de-excitation (Transition ii, Fig. 1) of electrons in the excited state back into the ground state, $B>>1 / \tau$, one approximates $B+1 / \tau \square B$ and equations (6) and (11) 
become:

$$
\begin{aligned}
& n_{e}\left(r^{\prime}, t\right)=\frac{A n_{g}\left(r^{\prime}, 0\right)}{B}\left(1-e^{-B t}\right) \quad \text { for } 0<t<t_{o}, \\
& n_{e}\left(r^{\prime}, t\right)=n_{e}\left(r^{\prime}, t_{o}\right) e^{-B t} \quad \text { for } t>t_{o} .
\end{aligned}
$$

The luminescence intensity $L_{O N}(t)$ and $L_{O F F}(t)$ will be found from:

$$
\begin{aligned}
& L_{O N}(t)=\int_{0}^{\infty} \frac{n_{e}\left(r^{\prime}, t\right)}{\tau\left(r^{\prime}\right)} d r^{\prime}=\frac{A\left(1-e^{-B t}\right)}{B} \int_{0}^{\infty} n_{g}\left(r^{\prime}, 0\right) d r^{\prime}=\frac{A n_{o}}{B}\left(1-e^{-B t}\right), \\
& L_{O F F}(t)=\int_{0}^{\infty} \frac{n_{e}\left(r^{\prime}, t_{o}\right)}{\tau\left(r^{\prime}\right)} e^{-B t} d r^{\prime}=e^{-B t} \int_{0}^{\infty} \frac{n_{e}\left(r^{\prime}, t_{o}\right)}{\tau\left(r^{\prime}\right)} d r^{\prime}=D e^{-B t}
\end{aligned}
$$

where $D$ is a constant which depends on the experimental conditions.

In these cases the characteristic time $\tau=1 / B$ for the luminescence intensity both during and after the pulse is independent of both the density parameter $\rho^{\prime}$, and the dimensionless distance parameter $r^{\prime}$, and therefore the intensity can be described by simple exponential functions. The analytical equations (22) and (23) can be used to fit the luminescence intensity during and after the IR pulse in a TR-IRSL experiment, and they should be applicable under conditions of strong de-excitation, $B>>1 / \tau$.

In the cases where the parameters $B$ and $1 / \tau$ are approximately of the same order of magnitude, it is not possible to obtain an analytical equation, and the luminescence intensity $L_{O N}(t)$ during the IR pulse must be evaluated by numerically integrating equations (12) and (16).

\section{COMPARISON OF ANALYTICAL EQUATIONS WITH EXPERIMENTAL DATA}

Previously published quantitative analysis of TR-IRSL data concerned mainly the emission measured after the excitation has been turned off (see for example Morthekai et al., 2012 and Pagonis et al., 2012b). In this section we present two examples in which both parts of the TR-IRSL signal are fitted using the new analytical equations.

As was discussed in detail in Section 2 of this paper, the behavior of the TR-signals may depend on the relative values of the parameters $B$ and $1 / \tau$. In this section we assume that the TR-IRSL signals are described by the condition $B<<1 / \tau$, since they provide the best fitting to the experimental data. However, the other two possibilities of $B>>1 / \tau$ and $B \sim 1 / \tau$ cannot be excluded, and may be prevalent for other types of samples. 
Figure 5a shows the rising part of a TR-IRSL curve during the ON-time of $50 \mu$ s for the FL1 feldspar sample described in the experimental section. The signal was measured for a stimulation temperature of $50^{\circ} \mathrm{C}$, after the sample was given a dose of $61.8 \mathrm{~Gy}$, and preheated to $280^{\circ} \mathrm{C}$ for $60 \mathrm{~s}$. The experimental data has been normalized to the maximum TR-IRSL intensity reached at the end of the excitation period. The analytical equation from the previous section is used to fit the data in Fig. 5a during the IR stimulation pulse of $50 \mu \mathrm{s}$, in the form:

$$
L_{\text {ON }}(t)=D\left[1-\exp \left[-\rho^{\prime} \ln (z b t)^{3}\right]\right]+b g d \quad \text {. }
$$

The parameters used to fit the data in Fig. 5a are the charge density $\rho^{\prime}$, the tunneling frequency $b$, and the constant background parameter bgd. The best fitting parameters are $b=(4.6 \pm 0.1) \times 10^{6} s^{-1}, \rho^{\prime}=0.020 \pm 0.001$, and the background was of the order of $1 \%$ of the maximum signal.

The fitted line in Fig. 5a and the residuals shown below indicate a robust fit, although they deviate up to $\sim 8 \%$ from the data points in the beginning and towards the end of the light excitation pulse. According to Jain and Ankjærgaard (2011), the light emitted during the stimulation pulse is dominated by tunnelling from the excited state, but has a small ( 5\%) contribution from another (slower) recombination route, such as phonon assisted migration through the band tail states. As this is not accounted for in the fitting, this could partly explain the deviation of the fit from the data towards the end of the stimulation pulse. The deviation in the initial $t<5 \mu$ s part of the TR-IRSL curve is likely to be caused by $B<<1 / \tau$ not being valid at small times, see Section 3.3. Despite this, the general trend of the TR-IRSL behaviour during the light pulse is satisfactorily described by the analytical equations.

Fig. 5b illustrates the data measured following the de-excitation TR-IRSL curve shown in Fig. 5a. The TR-IRSL OFF-time signal in Fig. 5b was fitted using the analytical equation in the previous section in the form:

$$
L_{\text {OFF }}(t)=D\left\{\exp \left[-\rho^{\prime} \ln (z b t)^{3}\right]-\exp \left[-\rho^{\prime} \ln \left[z b\left(t+t_{o}\right)\right]^{3}\right]\right\}+b g d
$$

The width of the excitation pulse used in the experiment was $t_{o}=50 \mu \mathrm{s}$. It was found that the deexcitation data in Fig. 5b could be fitted with the same parameters density $\rho^{\prime}, b$ as in Fig. 5a. The residuals are shown underneath the graph, they are of the order of $6 \%$ of the intensity of the TR- 
IRSL signal, indicating that the curve shape can be described adequately by tunneling behavior. Note that we also here observe a deviation between the fit and the experimental data for $t<5 \mu \mathrm{s}$ as in the previous figure.

Figure 6a and 6b show the rising and decaying part of a TR-IRSL curve for feldspar sample 951002FK which was described in the experimental section. The signal was measured for a stimulation temperature of $50^{\circ} \mathrm{C}$, after the sample was given a dose of $70 \mathrm{~Gy}$, and preheated to $250^{\circ} \mathrm{C}$ for $60 \mathrm{~s}$. The analytical equation from the previous section are again used to fit the data in Fig. $6 \mathrm{a}$ and Fig. $6 \mathrm{~b}$ with the width of the excitation pulse $t_{o}=500 \mu \mathrm{s}$.

The best fitting parameters for Fig. 6a were $b=(2.0 \pm 0.1) \times 10^{6} s^{-1}$ and $\rho^{\prime}=0.020 \pm 0.001$ and the background was of the order of $6 \%$ of the overall signal. A slightly adjusted value of $b=(2.6 \pm 0.1) \times 10^{6} \mathrm{~s}^{-1}$ was obtained for Fig. $6 \mathrm{~b}$, with the background of the order of $4 \%$ of the overall signal. The residuals are shown underneath the graph, they are of the order of $6 \%$ of the intensity of the TR-IRSL signal in Fig. 6a, and of the order of 2\% for Fig. 6b.

\section{DISCUSSION AND CONCLUSIONS}

In this paper it was demonstrated how typical TR-IRSL signals can be analyzed in the microseconds time scale, by using the tunneling model of random defects. The main assumption in the present model is that very few electrons are raised into the excited state during the optical excitation stage.

It is important to note that there may be some discrepancies when trying to fit the two parts of the TR signal using the same set of model parameters $\rho^{\prime}, b$. Such discrepancies between the fitting parameters most likely indicate the presence of a significant contribution from migration through the band tail states prior to recombination, as discussed in Jain and Ankjærgaard (2011), Poolton et al. (2009), Kars et al. (2013). Pagonis et al. (2012b) analyzed a series of TR-IRSL signals from 4 feldspar samples using a linear combination of an exponential and a stretched exponential function, with the latter function discussed in Berberan-Santos et al., (2005) and Berberan-Santos (2008). The analysis of Pagonis et al. (2012b) assumed that migration through the band tail states followed by direct recombination will contribute to the relaxation signal, especially at elevated stimulation temperatures. In the model of Jain and Ankjærgaard (2011), the authors also concluded that their TR data contained a significant band 
tail contribution, depending on the stimulation light and the stimulation temperature. It can be expected that as the stimulation temperature is increased, the contribution of the band tail signal in luminescence signal might become more dominant compared to the fast tunneling signal originating from the excited state.

An important result from the model described in this paper is that the shape of the relaxation signals after the LEDs have been turned off depends on the duration of the excitation $t_{o}$, as shown in Figure 4b. This is an important prediction from the model that needs to be confirmed experimentally. Additional experiments can be carried out with other photon energies (e.g. blue LEDs and green LEDs), in order to confirm the predictions of the model.

In order to ascertain whether the conclusions drawn from the model apply to other samples and other types of experiments, further experimental work needs to be carried out with different types of thermal and optical treatments of feldspar samples, with different optical stimulation wavelengths, and with different lengths of the excitation pulses,

It is noted that in time-resolved experiments one typical adds thousands of short pulses, in order to construct the time-resolved signals presented in the figures of this paper. It is therefore important to know to which extent the concentration of electrons in the traps decreases during the complete experimental procedure. In these type of experiments, it is estimated that the trap is typically depleted by only 5-10\% over the whole duration of the experiment. We therefore feel that the model presented here will be applicable mainly for the pulses measured during the beginning of the experiment, and that the agreement between model and experiment will become more questionable for the later stages of time-resolved experiments which last more than a few seconds.

An additional important conclusion from the experimental data analyzed in Figures 5 and 6 is the low value of the tunneling frequency factor $b \sim 10^{6} s^{-1}$. Jain et al. (2015) showed that

analysis of their CW-IRSL data yields also a value of $b \sim 10^{6} s^{-1}$, similar to the low value obtained in the time-resolved experiments described in this paper.

\section{ACKNOWLEDGEMENTS}

The authors thank Dr P Morthekai for providing us with a digital copy of his TR-IRSL data for sample FL1. Dr. Vasilis Pagonis is grateful for the financial support during several visits at DTU Nutech, Risø campus, in Roskilde, Denmark. Dr. Christina Ankjærgaard acknowledges 
funding by Netherlands Organisation for Scientific Research, NWO VENI (grant 863.13.023) during this work. 


\section{REFERENCES}

Andersen, M. T., Jain, M., and Tidemand-Lichtenberg, P., 2012. Red-IR stimulated luminescence in K-feldspar: Single or multiple trap origin?. J. Appl. Phys. 112, 043507.

Ankjærgaard, C., Jain, M., Kalchgruber, R., Lapp, T., Klein, D., McKeever, S.W.S., Murray, A.S., Morthekai, P., 2009. Further investigations into pulsed optically stimulated luminescence from feldspars using blue and green light. Radiat. Meas. 44, 576-581.

Bailiff, I.K., Poolton, N.R.J., 1991. Studies of charge transfer mechanisms in feldspars.

Nucl. Tracks Radiat. Meas. 18, 111-118.

Berberan-Santos, M.N. , Boduno, E.N., and Valeur, B., 2005. Mathematical functions for the analysis of luminescence decays with underlying distributions 1. Kohlrausch decay function (stretched exponential). Chemical Physics 315 , 171-182.

M. N. Berberan-Santos ed., 2008. Fluorescence of Supermolecules, Polymers and Nanosystems, Springer, Berlin.

Bøtter-Jensen L, McKeever S W S and Wintle A G 2003 Optically Stimulated Luminescence Dosimetry (Amsterdam: Elsevier)

Chen, R. and Pagonis, V., 2011. Thermally and Optically Stimulated Luminescence: A Simulation Approach (Chichester: Wiley and Sons).

Clark, R.J. and Bailiff, I.K. , 1998. Fast time-resolved luminescence emission spectroscopy in some feldspars. Radiat. Meas. 29, 553.

Clark, R.J. , Bailiff, I.K., and Tooley, M.J. , 1997. A preliminary study of time-resolved luminescence in some feldspars. Radiat. Meas. 27, 211.

Chithambo, M.L. and Galloway, R.B. , 2000. A pulsed light-emitting-diode system for 
stimulation of luminescence. Meas. Sci. Technol. 11, - 418.

Denby, P.M., Bøtter-Jensen, L. , Murray, A.S., Thomsen, K.J., Moska, P. , 2006. Application of pulsed OSL to the separation of the luminescence components from a mixed quartz/feldspar sample. Radiat. Meas. 41, - 774-779.

Duller, G.A.T. and Bøtter-Jensen, L. ,1993. Luminescence from potassium feldspars stimulated by infrared and green light,” Radiat. Prot. Dosim. 47, 683-688.

Duller, G.A.T., 1997. Behavioural studies of stimulated luminescence from feldspars. Radiat. Meas. 27, 663-694.

Huntley, D.J., Lamothe, M., 2001. Ubiquity of anomalous fading in K-feldspars and the measurement and correction for it in optical dating. Canad. J. Earth Sci. 38, 1093-1106.

Huntley, D.J., 2006. An explanation of the power-law decay of luminescence. J. Phys. Cond. Matt. 18, 1359-1365.

Jain, M., Sohbati, R., Guralnik, B. , Murray, A.S. , Kook, M. , Lapp, T., Prasad, A.K. , Thomsen, K.J., Buylaert, J. P., 2015. Kinetics of infrared stimulated luminescence from feldspars. Radiat. Meas. 81, 242-250.

Jain, M , Guralnik, B and Andersen, M T. 2012. Stimulated luminescence emission from localized recombination in randomly distributed defects J. Phys.: Condens. Matter 24, 385402 (12pp)

Jain, M., Ankjærgaard, C., 2011. Towards a non-fading signal in feldspar: insight into charge transport and tunneling from time-resolved optically stimulated luminescence. Radiat. Meas. 46, 292-309. 
Kitis, G. and Pagonis, V., 2013. Analytical solutions for stimulated luminescence emission from tunneling processes in random distributions of defects. J. Lum., 137, 109-115.

Kars, R.H., Wallinga, J., Cohen, K.M., 2008. A new approach towards anomalous fading correction for feldspar IRSL dating-tests on samples in field saturation. Radiat. Meas. 43, 786790.

Kars, R.H., Poolton, N.R.J., Jain, M., Ankjaergaard, C., Dorenbos, P., Wallinga, J., 2013. On the trap depth of the IR-sensitive trap in Na- and K-feldspar. Radiat Meas 59, 103-113.

Larsen, A., Greilich, S., Jain, M., Murray, A.S., 2009. Developing a numerical simulation for fading in feldspar. Radiat. Meas. 44, 467-471.

Li, B., Li, S.-H., 2010. Thermal stability of infrared stimulated luminescence of sedimentary Kfeldspar. Radiat. Meas. 46, 29-36

Li, B., Li, S.-H., 2008. Investigations of the dose-dependent anomalous fading rate of feldspar from sediments. J. Phys. D: Appl. Phys. 41, 225502.

Morthekai, P., J. Thomas, J., M.S. Padian, M.S., V. Balaram,V. and A.K. Singhvi, A.K., 2012. Variable range hopping mechanism in band-tail states of feldspars: A time-resolved IRSL study. Radiation Measurements, 47: 857-863.

Pagonis, V., Lawles, J., Chen, R., Chithambo, M.L., 2011. Analytical expressions for timeresolved optically stimulated luminescence experiments in quartz. Journal of Luminescence 131 , 1827-1835.

Pagonis, V., Phan, H., Ruth, D., Kitis, G., 2013. Further investigations of tunneling recombination processes in random distributions of defects. Radiat. Meas. 58, 66-74.

Pagonis, V., Jain, M., Murray, A. S., Ankjærgaard, C., Chen, R., 2012a. Modeling of the shape of infrared stimulated luminescence signals in feldspars. Radiation Measurements, 47, 870-876. 
Pagonis, V., Morthekai, P., Singhvi, A.K., Thomas, J., Balaram, V., Kitis, G., Chen, R., $2012 b$. Time-resolved infrared stimulated luminescence signals in feldspars: Analysis based on exponential and stretched exponential functions. Journal of Luminescence 132, 2330-2340.

Pagonis, V., Jain M., Thomsen, K.J., Murray, A.S., 2014a. On the shape of continuous wave infrared stimulated luminescence signals from feldspars: a case study. J. of Lumin. 153, 96-103.

Pagonis, V., Morthekai, P. and Kitis, G., 2014b. Kinetic analysis of thermoluminescence glow curves in feldspars: evidence for a continuous distribution of energeirgies. 2014b Geochronometria 41, 168-177.

Pagonis, V. and Kitis, G. Mathematical aspects of ground state tunneling models in luminescence materials, 2015 . J. of Lumin. 168, 137-144

Polymeris, G. S., Giannoulatou, V., Sfampa, I. K., Tsirliganis, N. C., Kitis, G. , 20014. Search for stable energy levels in materials exhibiting strong anomalous fading: the case of apatites. J. of Lumin., 153, 245-251.

Poolton, N.R.J., Wallinga, J., Murray, A.S., Bulur, E., Bøtter-Jensen, L., 2002a. Electrons in feldspar I: on the wave function of electrons trapped at simple lattice defects. Phys. Chem. Minerals 29, 210-216.

Poolton, N.R.J., Ozanyan, K.B., Wallinga, J., Murray, A.S., Bøtter-Jensen, L., 2002b. Electrons in feldspar II: a consideration of the influence of conduction band-tail states on luminescence processes. Phys. Chem. Minerals 29, 217-225.

Poolton, N.R.J., Kars, R.H., Wallinga, J., Bos, A.A.J., 2009. Direct evidence for the participation of band-tails and excited-state tunneling in the luminescence of irradiated feldspars. J. Phys. Cond. Matt 21, 485505.

Sanderson, D.C.W. and Clark, R.J., 1994. Pulsed photostimulated luminescence of alkali feldspars. Radiat. Meas. 23, - 633. 
Sfampa, I.K., Polymeris, G.S., Pagonis, V., Thodosoglou, E., Tsirliganis, N.C., and Kitis, G., 2015. Correlation of basic TL, OSL and IRSL properties of ten K-feldspar samples of various origin. Nuclear Instruments and Methods in Physics Research B. , 359, 89-98.

Sfampa, I.K., Polymeris, G.S., Tsirliganis, N.C., Pagonis, V. and Kitis, G., 2014. Prompt isothermal decay of thermoluminescence in an apatite exhibiting strong anomalous fading. Nuclear Instruments and Methods in Physics Research B 320, 57-63.

Tachiya, M., Mozumder A., 1974. Decay of trapped electrons by tunnelling to scavenger molecules in low temperature glasses. Chemical Physics Letters 28, 87-89.

Thomsen, K.J., Murray, A.S., Jain, M., Bøtter-Jensen, L., 2008. Laboratory fading rates of various luminescence signals from feldspar-rich sediment extracts. Radiat. Meas. 43, 14741486

Thomsen, K.J., Murray, A.S., Jain, M., 2011. Stability of IRSL signals from sedimentary K-feldspar samples. Geochronometria 38, 1-13.

Tsukamoto, S. Denby, P.M. , Murray, A.S. , Bøtter-Jensen, L. , 2006. Time-resolved luminescence from feldspars: New insight into fading. Radiat. Meas. 41 , 790.

Visocekas R, Spooner N A, Zink A and Blank P , 1994. Tunnel afterglow, fading and infrared emission in thermoluminescence of feldspars. Radiat. Meas. 23 ,377-85

Visocekas, R., 1985. Tunneling radiative recombination in labradorite: its association with anomalous fading of thermoluminescence. Nucl. Tracks Radiat. Meas. 10, 521-529.

Wintle, A.G., 1973. Anomalous fading of thermoluminescence in mineral samples. Nature 245, 143-144. 


\section{FIGURE LEGENDS}

\section{Figure 1}

Simplified band diagram showing the feldspar luminescence transitions considered in the model and discussed in the text: Transition (i) denotes the optical transition between the ground state of the trapped electron to the excited state, and transition (ii) is de-excitation back into the ground state. Transition (iii) is direct tunneling from the excited state of the trapped electron to the recombination center. The figure is adapted after Jain and Ankjærgaard (2011) and Jain et al. (2012; 2015)

\section{Figure 2}

(a) The distribution of electrons $n_{e}\left(r^{\prime}, t\right)$ in the excited state calculated using equation (6) and for the set of parameters $\rho^{\prime}=0.010, n_{0}=10^{8} \mathrm{~cm}^{-3}, A=10^{3} \mathrm{~s}^{-1}, s=10^{8} \mathrm{~s}^{-1}, B=10^{5} \mathrm{~s}^{-1}$. As the excitation time increases during the pulse, the distribution $n_{e}\left(r^{\prime}, t\right)$ increases with the excitation time, and also shifts to higher values of the distance $r^{\prime}$. At long excitation times $t=25 \mu \mathrm{s}$ the distribution $n_{e}\left(r^{\prime}, t\right)$ starts to approach a saturation/equilibrium value.

(b) Example of $L_{O N}(t)$ calculated from equation (12) by numerical integration for the same set of parameters as in (a), and for two values of the charge density $\rho^{\prime}=0.001$ and $\rho^{\prime}=0.010$

\section{Figure 3}

(a) The distribution of electrons $n_{e}\left(r^{\prime}, t\right)$ in the excited state calculated using equation (14) for the charge density $\rho^{\prime}=0.010$, and for different times after the stimulating IR light has been turned off. As the time $t$ elapses after the end of the pulse, the distribution $n_{e}\left(r^{\prime}, t\right)$ decreases, and shifts to higher values of the distance $r^{\prime}$.

(b) Example of $L_{O F F}(t)$ calculated by numerical integration of equation (16) for the same set 
of parameters as in Figure 2.

\section{Figure 4}

(a) Simulation of several pulses of different excitation periods $t_{o}$, using the same model parameters as in Figure 2.

(b) The decaying part of the pulses in (a) is shown normalized to the start of the decaying period. The duration of the excitation period affects the rate of decay of the pulses.

\section{Figure 5}

TR-IRSL curve obtained using feldspar sample FL1 described in the text. The signal was measured for a stimulation temperature of $50^{\circ} \mathrm{C}$, after the sample was given a dose of $61.8 \mathrm{~Gy}$, and preheated to $280^{\circ} \mathrm{C}$ for $60 \mathrm{~s}$. The experimental data has been normalized to the maximum TR-IRSL intensity reached at the end of the excitation period.

(a) Signal measured during IR pulse of $50 \mu$ duration

(b) Signal measured during the relaxation period of $100 \mu$ s, after the IR LEDs have been turned off. The solid lines represent the analytical equations, with the best fitting parameters given in the text.

\section{Figure 6}

TR-IRSL curve obtained using potassium rich feldspar (lab. code 951002 FK). The signal was measured at a stimulation temperature of $50^{\circ} \mathrm{C}$, after the sample was given a dose of $70 \mathrm{~Gy}$, and then preheated to $250^{\circ} \mathrm{C}$ for $60 \mathrm{~s}$.

(a) Signal measured during IR pulse of $500 \mu$ s duration

(b) Signal measured during the relaxation period of $300 \mu$ s, after the IR LEDs have been turned off. The solid lines represent the analytical equations, with the best fitting parameters given in the text. 
Figure 1

Conduction band

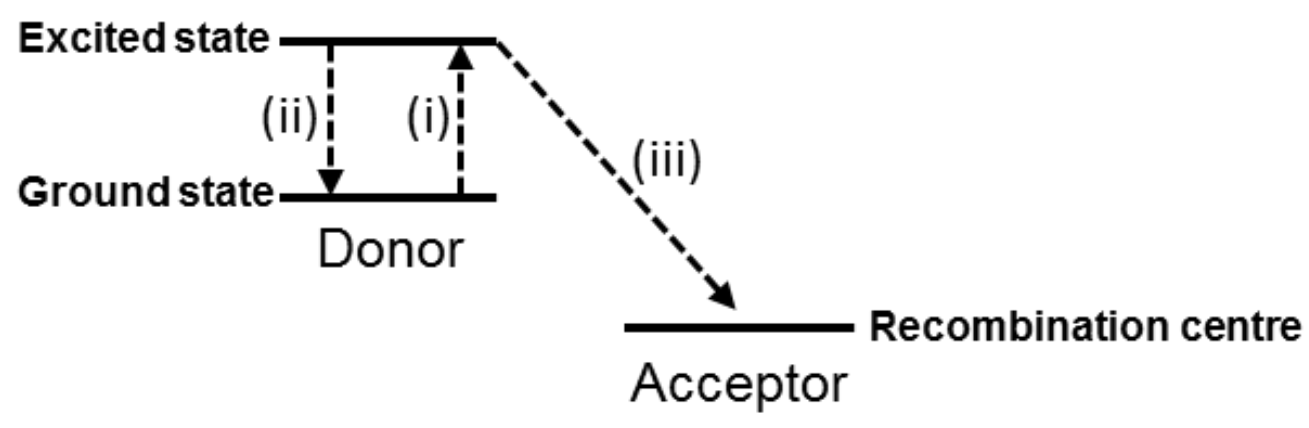

Valence band 
Figure 2
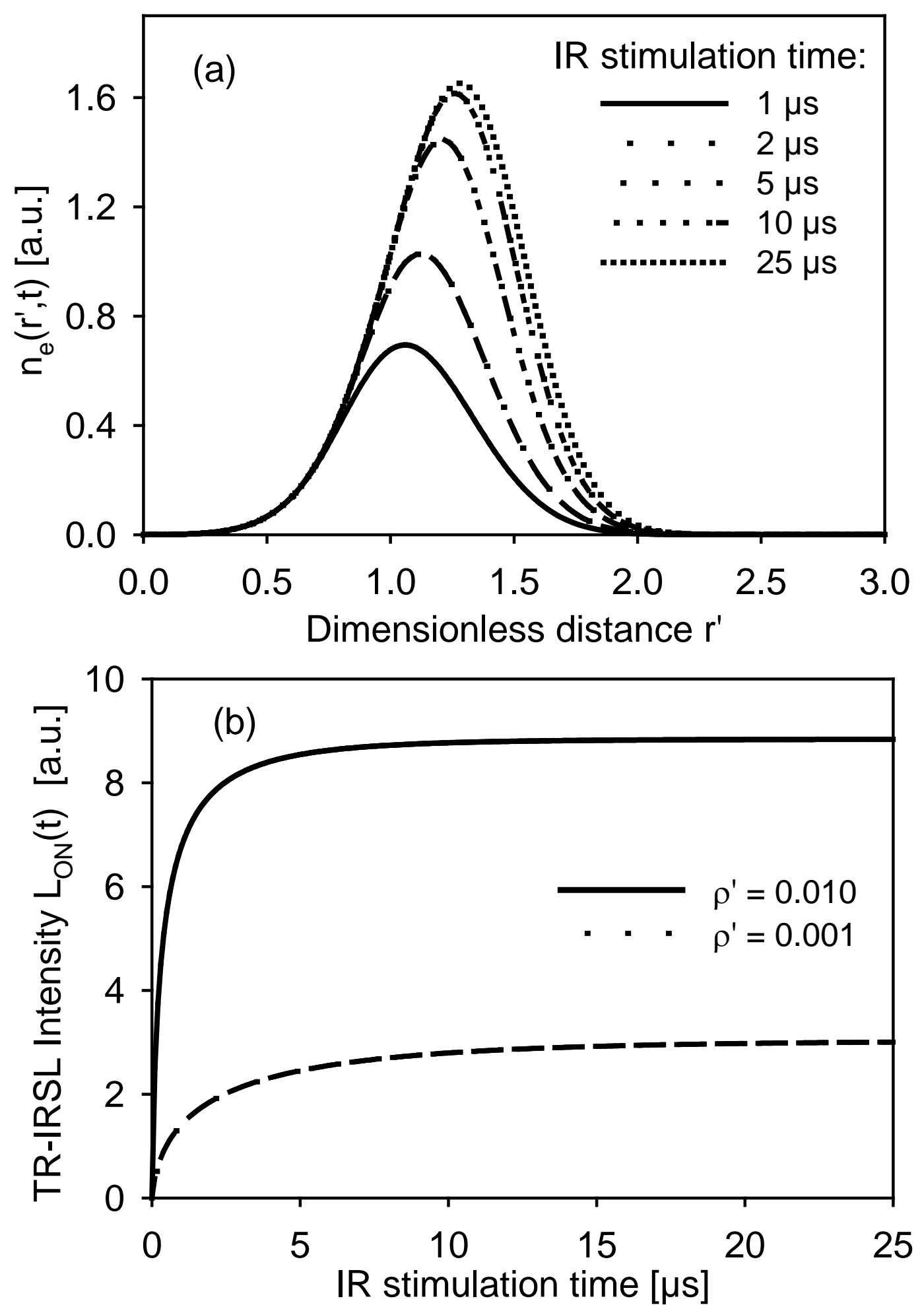
Figure 3
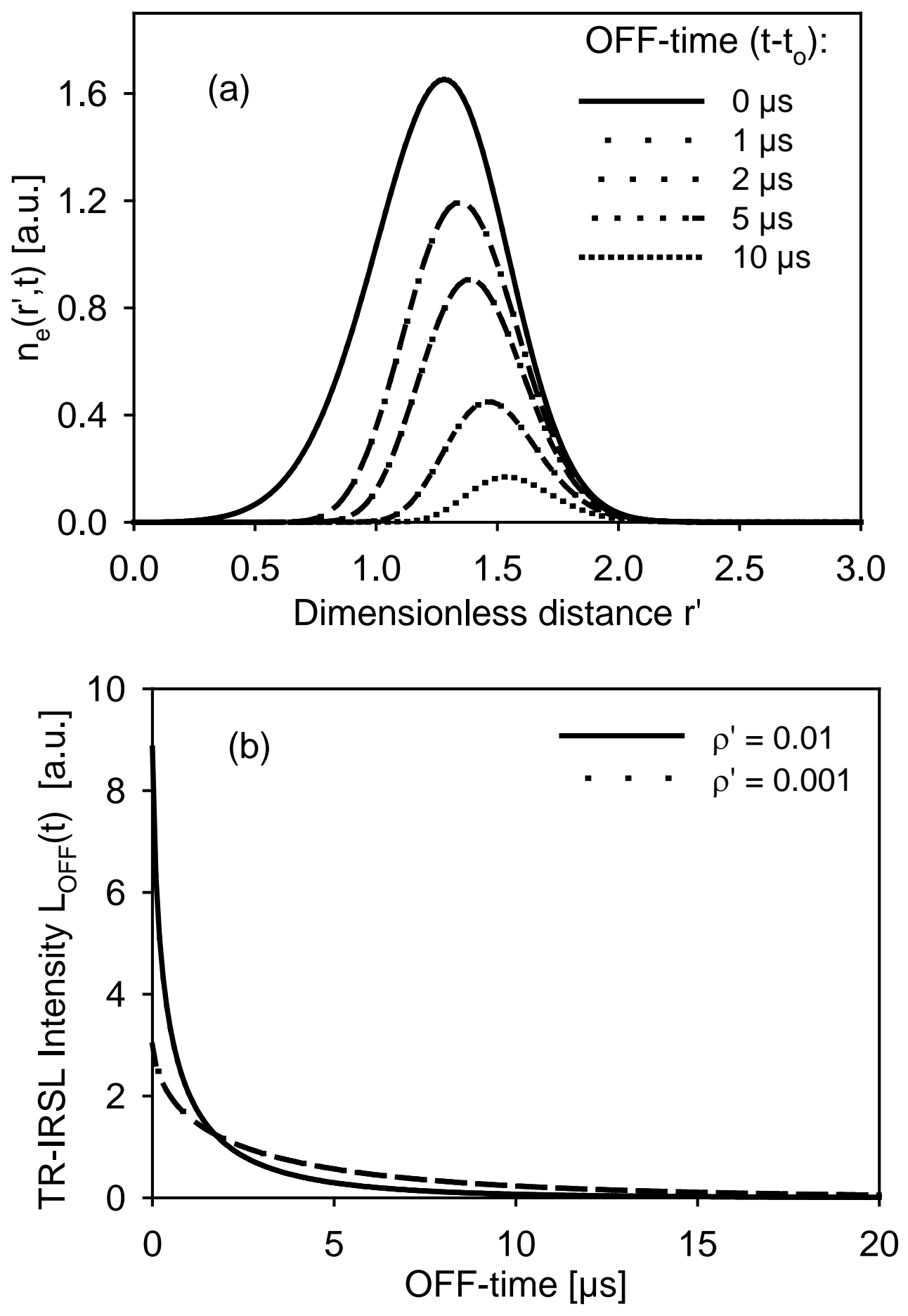
Figure 4
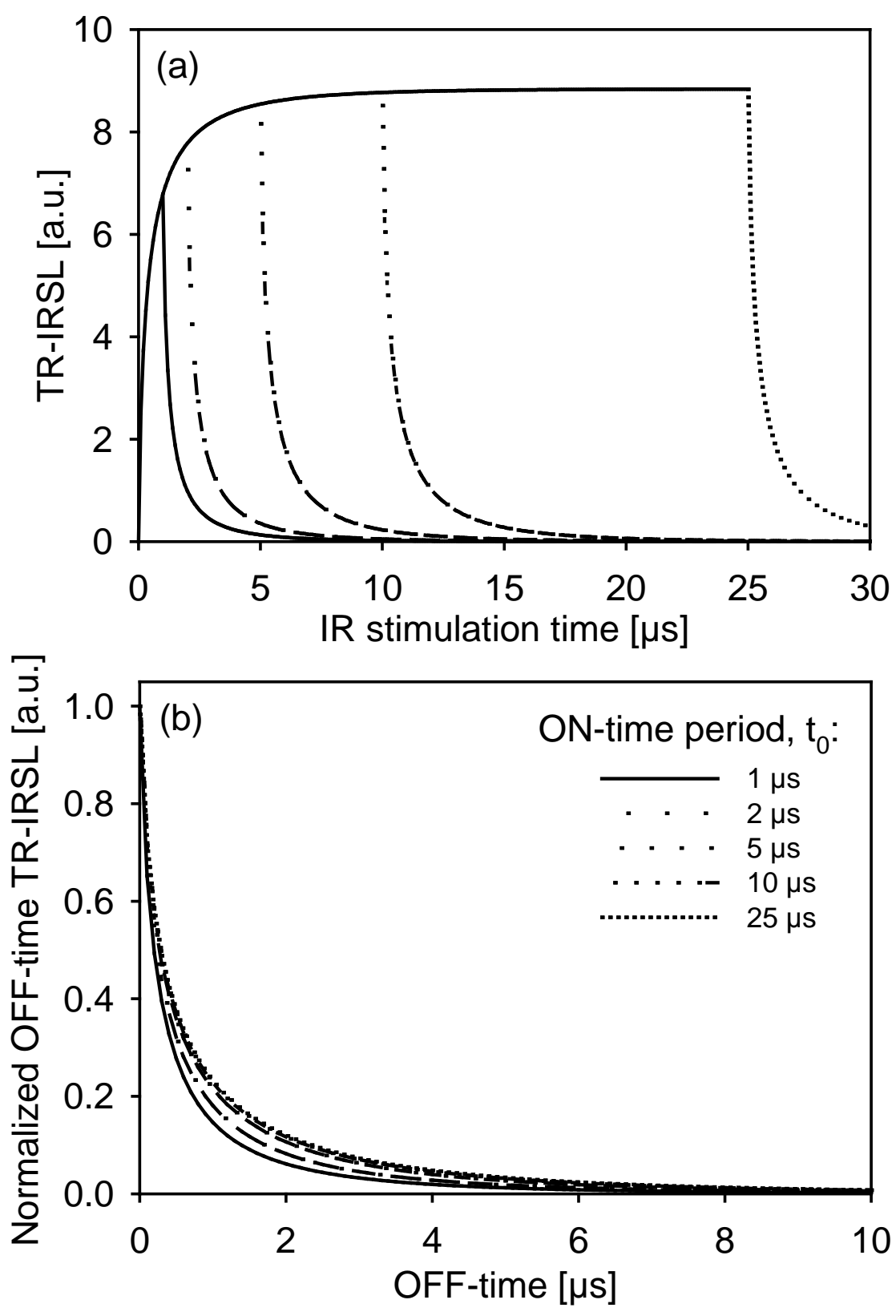
Figure 5

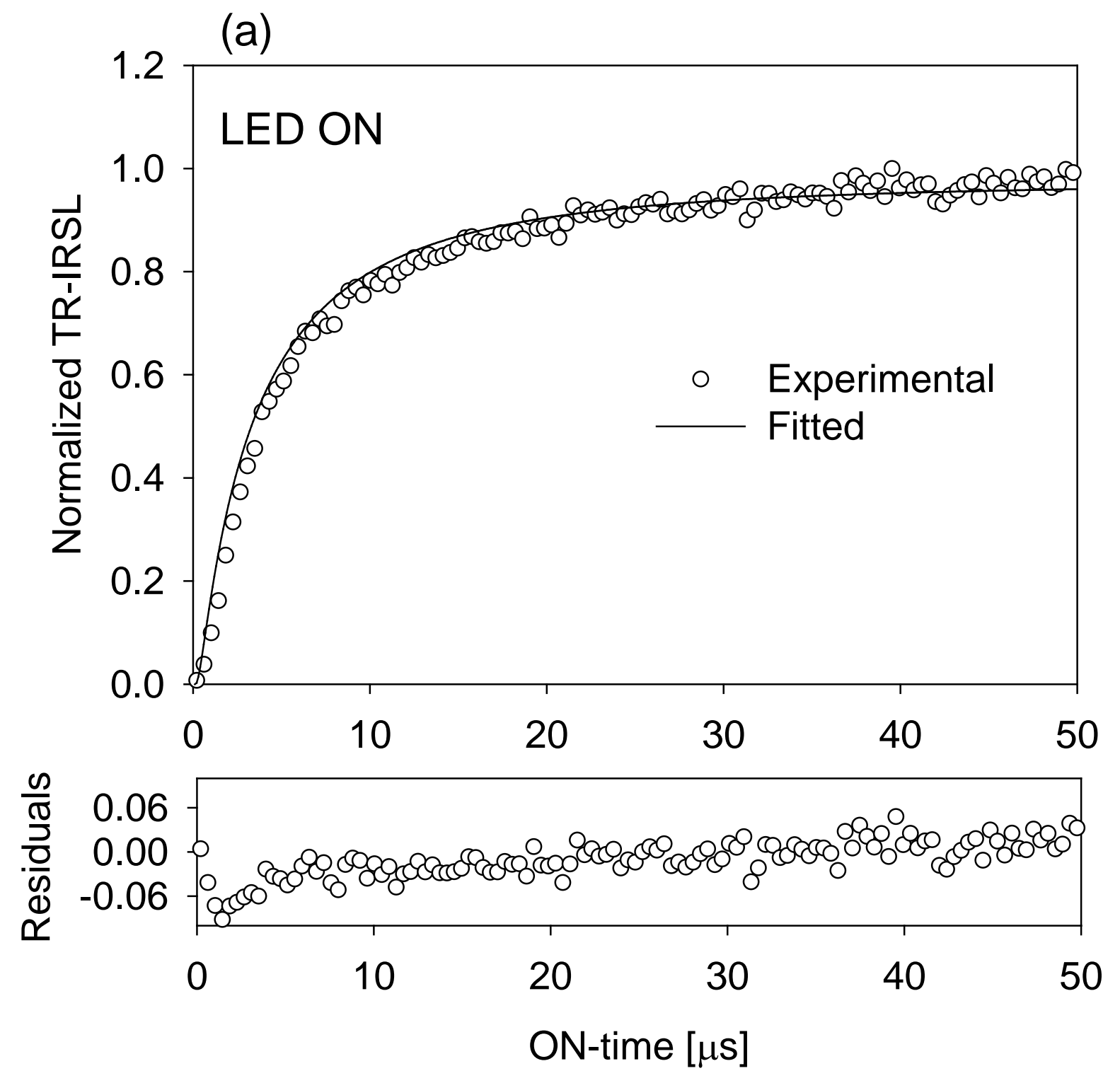


(b)

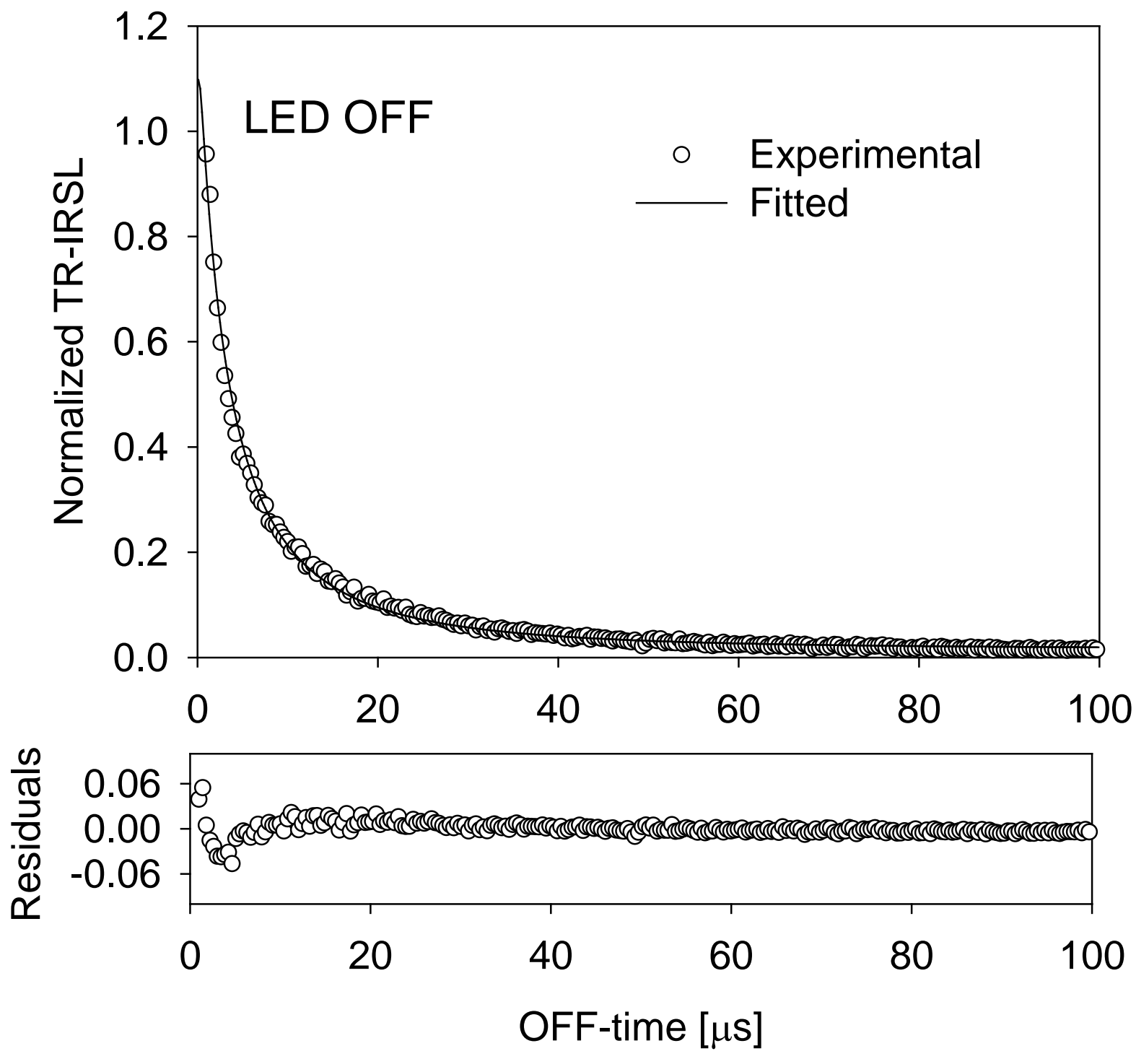


Figure 6

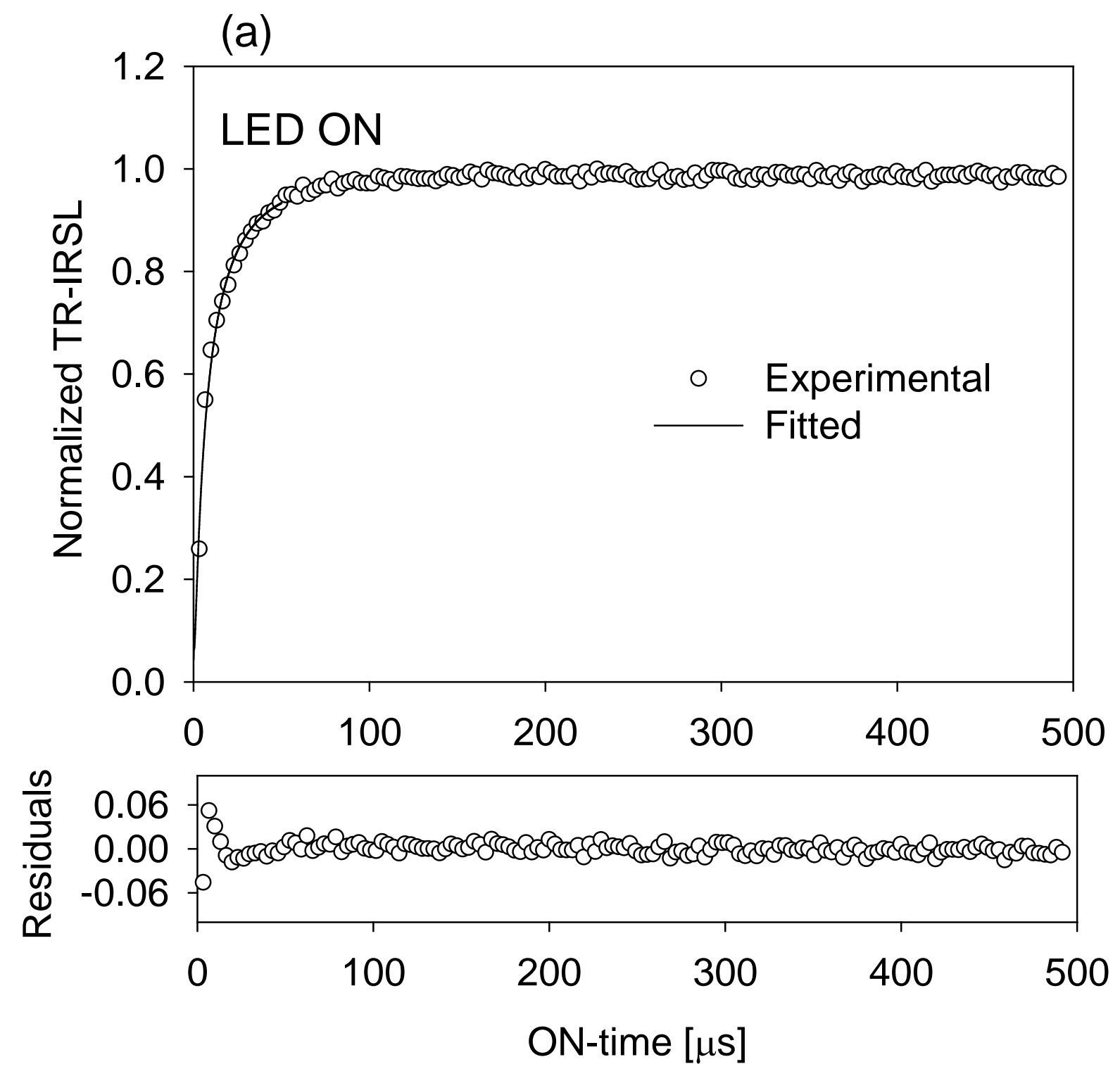


(b)

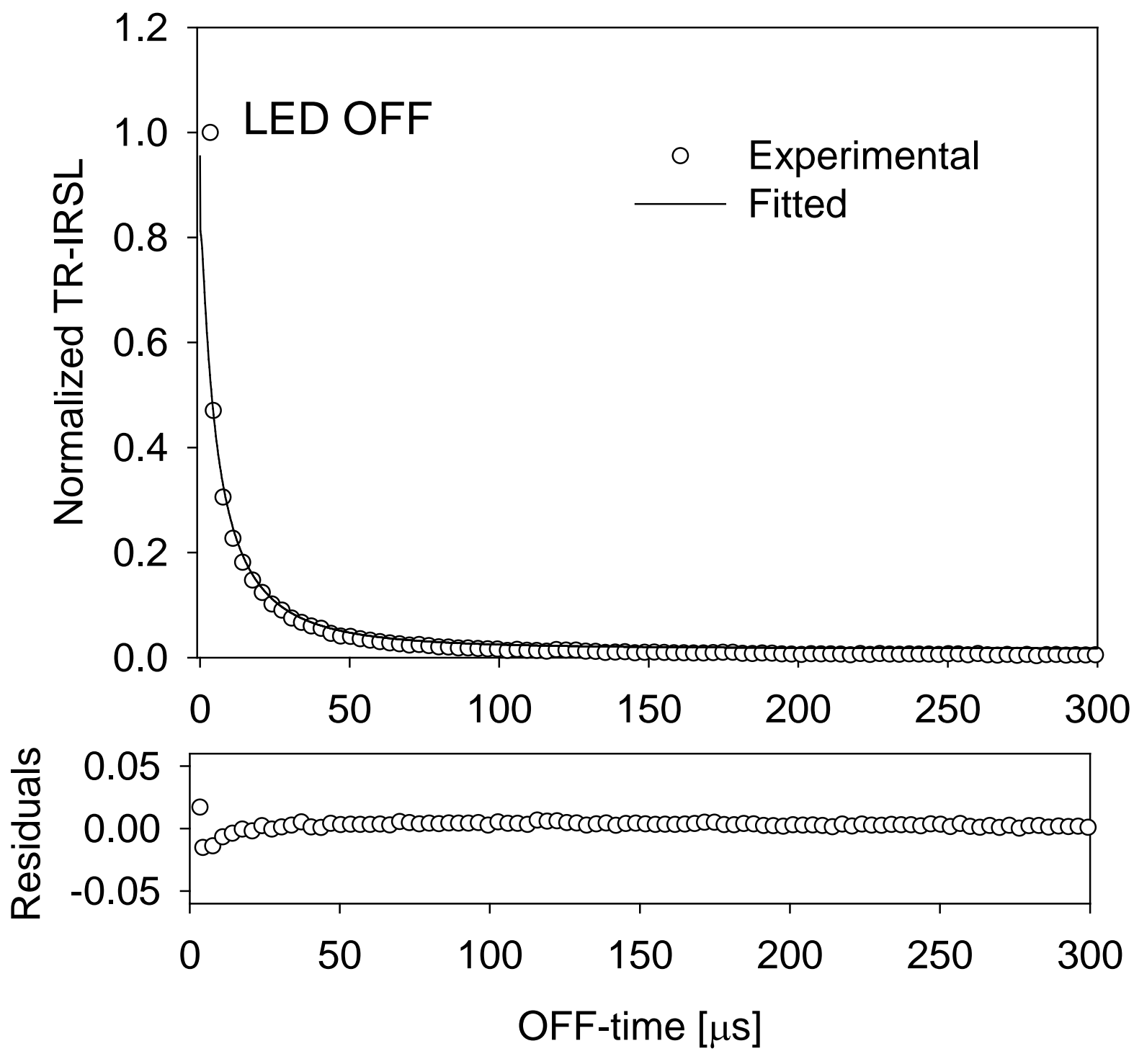

